\title{
The influence of the electromagnetic field on the electric properties of water
}

\author{
Redouane Mghaiouini ${ }^{1,2, *}$, Abderrahmane Elmlouky ${ }^{2}$, Reddad El Moznine ${ }^{2}$, Mohamade Monkade ${ }^{2}$ \\ and Abdeslam El Bouari ${ }^{1}$ \\ ${ }^{1}$ Department of chemistry, physical chemistry laboratory applied materials, Faculty of Sciences-Ben M'sik, \\ Hassan II University, Casablanca, Morocco \\ ${ }^{2}$ Department of Physic condensed Matter Laboratory, Faculty of Sciences, Chouaib Doukkali University, \\ El-Jadida, Morocco
}

\begin{abstract}
This paper presents an experimental study to investigate the effect of using the electromagnetic field on the electric conductivity and dielectric properties of treated tap water by aqua $4 \mathrm{D}$ system according to the time of exposition in a closed water circulation circuit. There is a portion where there is an electromagnetic field obtained by the electromagnetic device. This work includes tap water circulation in the region of the electromagnetic field for $5 \mathrm{~min}, 10,15,20 \mathrm{~min}$. The dielectric and electrical properties were examined and analyzed using the technique impedance spectroscopy in the frequency range going from $0.1 \mathrm{~Hz}$ to $1 \mathrm{MHz}$.
\end{abstract}

To initiate the phenomena involving water after magnetization with the electromagnetic field. The results clearly show that the magnetic field reduces the dielectric constant and resistance of water and increase its electric conductivity. In this study, we also find that the electrical conductivity of magnetized water increases.

Keywords: water; magnetic; electric; electrochemical impedance spectroscopy.

\section{Introduction}

Magnetized water is described as water passing through an electromagnetic field. It is considered as low-cost and eco-friendly water treatment, with inexpensive installation fees and no energy consumption. Nevertheless, the impact of magnetism on the water is still the topic of controversy. There are numerous claims that magnetized water offers increased performance in terms of reducing scale ${ }^{1}$, increases in crop yield and germination 2,3 , health benefits ${ }^{4}$, alters $\mathrm{pH}^{5}$, improves water memory ${ }^{6}$, reduces water tension ${ }^{7}$, and improves the compressive and tensile strength of cement ${ }^{8}$, amongst others.

Due to the partial covalence of the hydrogen bond of water, electrons are not retained by single molecules but are readily distributed between clusters of water, resulting in coherent regions ${ }^{9}$. Furthermore, electromagnetic water has several relevant characteristics, namely a memory effect, a saturation effect, as well as the dielectric constant and the hardening and boiling point ${ }^{10}$ and electromagnetic radiation ${ }^{11}$.

The effect of the alternating electric field (AC, $100 \mathrm{GHz}$ to $1000 \mathrm{GHz}$ ) on both the static and dynamic characteristics of water was investigated in a previous *Corresponding author: Redouane Mghaiouini Email address: filagri1.maroc@gmail.com DOI: http://dx.doi.org/10.13171/mjc10502005181406rm research ${ }^{12}$. It was stated that the passage of a lowfrequency alternating electric current $(4-20 \mathrm{~Hz})$ across distilled, deionized water by using platinum electrodes induces the cooling of water ${ }^{13}$, which is a result that needs more clarification. The reason for the observed behavior is attributed to a decrease in water entropy related directly into an increase in lowdensity water.

Electric fields are supposed to accentuate the differences of properties among the ortho and para forms of water ${ }^{14}$. Moreover, electric fields decrease the dielectric constant of water ${ }^{15}$ because of the resulting partial or complete breakdown of the hydrogen-bonded network.

Pure water is known to conduct electricity poorly, yet it is not a perfect insulator since it always contains ions due to self-dissociation. The passage of an electric current induces electrolysis, thus generating $\mathrm{O}_{2}$ and $\mathrm{H}_{2}$ at the anode and the cathode respectively ${ }^{16}$. The resulting water stores variations in concentration for long periods (hours) ${ }^{17}$. On metallic electrodes, even relatively low tensions may have a significant influence on the orientation of water molecules and the positions of the ions ${ }^{18}$. The hydrogen atoms contained in the water are directed to the electrode by a negative potential of $-0.23 \mathrm{~V}$. In comparison, the

Received March 19, 2020

Accepted April 21, 2020

Published May 18, 2020 
positive potential of $+0.52 \mathrm{~V}$ inverts this phenomenon, both leading to a particular breaking of the hydrogen bond and a localized increase in density.

Liquid water can be influenced by magnetic fields 19 which contribute to its purification ${ }^{20}$. Water being diamagnetic, it levitates in potent magnetic fields (10 T, if comparedto the Earth magnetic field of 50 $\mu \mathrm{T})^{21}$. In simulations, lower magnetic fields $(0.2 \mathrm{~T})$, which are yet strong, were reported to increase the number of monomer water molecules ${ }^{22}$. However, it was surprisingly noticed that the tetrahedrally was increased simultaneously. Further investigations revealed that the magnetic field causes an increase in cluster size in liquid water ${ }^{23}$. Conversely, it was stated that the friction coefficient of water in thin films decreased in a magnetic field (0.16-0.53 T), implying that the hydrogen bonding strength may be reduced ${ }^{24}$.

High fields $\left(\mathrm{E} \approx \mathrm{V} \times \mathrm{nm}^{-1}\right)$ are also encountered (possibly in a surprising way) at the surface of hydrophilic molecules as a result of the partial charges upon the atoms and the small distances separating the surface and the first hydration layer. Hydrogenbonding is affected by high fields anisotropically, where hydrogen bonds are stronger longitudinally across the field but weaker orthogonally to the field ${ }^{25}$. These fields demonstrated this anisotropic influence (by molecular modelling) on the dynamic viscosity of water. However, when the fields are lower, translational and rotational movements can be reduced.

The application treated the water of higher ELF-EMF fields $(\approx 0.15 \mathrm{~T})$, then its relative permittivity (dielectric constant) was evaluated and compared to the one of tap water. The results indicated that the relative permittivity (dielectric constant) of the magnetized water was $3.7 \%$ higher than that of tap water over the studied frequency range of 1-10 GHz. It was suggested then that this behavior is the result of a higher molecular polarization in the treated water ${ }^{26}$.

To see the influence of the electromagnetic field on tap water precisely on the dipole moment through the quantity linked to the polarization under the electric field and the magnetic field on the arrangement of the clusters of water molecules and what are the new directions in the space are articulated in relation to the published work which is in the bibliography.

\section{Materials and methods}

\subsection{Equipment and physical characterization of the electromagnetic device}

Figure 1 shows an approximate diagram of the experimental manipulation for passing tap water through the circuit indicated on Experimental indication.

The experimental indication consists of:

A starting tank that contains a pump that pushes water towards the Aqua 4 D system (ISO 9001 certified) through a cylindrical tube of $50 \mathrm{~cm}$ in length and $5 \mathrm{~cm}$ in diameter passing towards the second tank then it returns to the starting tank for 30 seconds per cycle.

The tank contains $20 \mathrm{~L}$ of tap water at a temperature of $17.7^{\circ} \mathrm{C}$ and the temperature of the laboratory is $26^{\circ} \mathrm{C}$.

The electromagnetic field of constant intensity delivered by the Aqua $4 \mathrm{D}$ system is unknown but the device

operates at an electrical voltage of $220 \mathrm{~V}$ The electromagnetic device comprises two basic components:

-An electronic box pre-programmed to produce electromagnetic signals (EM).

-Tubes specifically designed for transmitting the EMC signal in the water. $20 \mathrm{~L}$ of water were used in each experiment to fill a plastic tank where the pump is submerged $(\mathrm{H}=1.8 \mathrm{~m}, \mathrm{Q}=1200 \mathrm{Lt} / \mathrm{hr}$.) as it can be seen in Figure 1. The water was circulated continuously for 160 minutes in each run. Tests were undertaken every 10 minutes to evaluate the electrical properties of water before and after the treatment by the electromagnetic field.

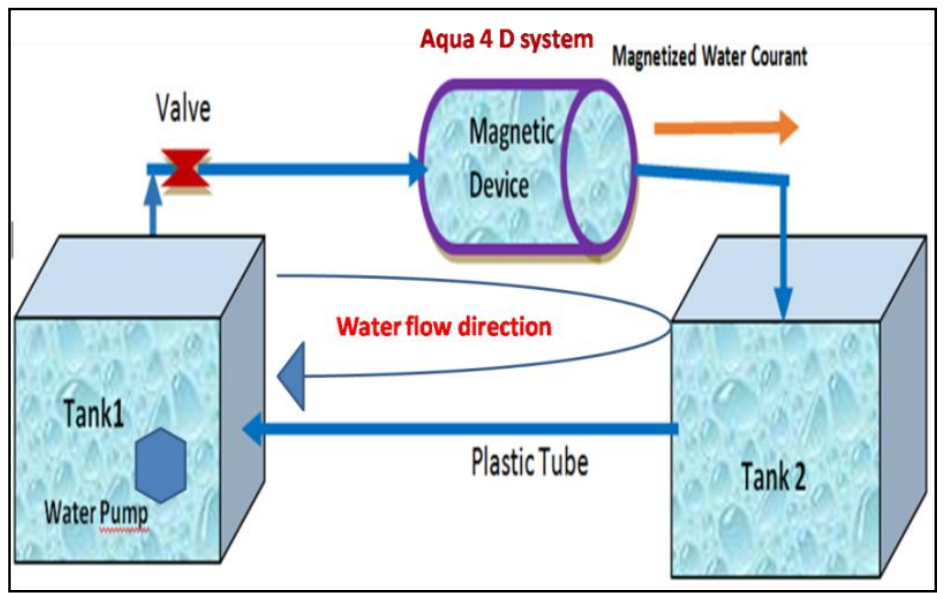

Figure 1. Equipment of Aqua-4D and Electromagnetic field generator 
We turn on the circuit, and after five minutes, we take a $100 \mathrm{ml}$ sample, then measuring the electrical impedance for each sample going from $5 \mathrm{~min}$ to 20 min by a step of 5 min between each sample. We measured the spectroscopy impedance of $100 \mathrm{~mL}$ of water not treated by the Aqua 4D system.

\subsection{Water properties}

\subsubsection{Tap water composition}

Table 1 summarizes the physico-chemical parameters of tap water and water treated by the electromagnetic field in order to show that these differences are due to the influence of the electromagnetic field.

Table 1. Physicochemical analysis of tap water and magnetized water.

\begin{tabular}{|c|c|c|}
\hline Settings & Tap water & Magnetized water \\
\hline $\mathrm{pH}$ & 7,69 & 8,25 \\
\hline Conductivity & $1695 \mu \mathrm{S} / \mathrm{Cm}$ & $971 \mu \mathrm{S} / \mathrm{Cm}$ \\
\hline TDS & $848 \mathrm{mg} / \mathrm{l}$ & $485 \mathrm{mg} / 1$ \\
\hline Salinity & $0,85 \mathrm{PSU}$ & $0,48 \mathrm{PSU}$ \\
\hline Ca & $78.5 \mathrm{mg} / \mathrm{l}$ & $79 \mathrm{mg} / 1$ \\
\hline oxydability & $0.41 \mathrm{mg} / 1$ & $0.49 \mathrm{~g} / 1$ \\
\hline Chlorure & $88.5 \mathrm{mg} / \mathrm{l}$ & $89 \mathrm{mg} / 1$ \\
\hline Temperature & $17,8^{\circ} \mathrm{C}$ & $17,1^{\circ} \mathrm{C}$ \\
\hline Mg & $23.83 \mathrm{mg} / \mathrm{l}$ & $23.9 \mathrm{mg} / 1$ \\
\hline alkalinity & $10.35{ }^{\circ} \mathrm{F}$ & $10.4^{\circ} \mathrm{F}$ \\
\hline TH or hydrometrictiter & $2.94 \mathrm{meq} / \mathrm{l}$ & $2.98 \mathrm{meq} / 1$ \\
\hline Ammonium & $0 \mathrm{mg} / \mathrm{l}$ & $0 \mathrm{mg} / \mathrm{l}$ \\
\hline Iron & $0 \mathrm{mg} / \mathrm{l}$ & $0 \mathrm{mg} / \mathrm{l}$ \\
\hline
\end{tabular}

\subsubsection{Water cluster model}

Logically, these water clusters models induce the icosahedron water cluster concept, which is based upon dense and less dense clusters equivalent to the opposite equilibrium. The less-dense structures of the bicycle $(2,2,2)$ arise from the most durable hydrogen bond, while dense structures (far left) take place when weaker but more several Van der Waals interactions prevail as shown in Figure 2.



Figure 2. Icosahedral cluster

\subsubsection{Hydrogen Bonding in Water}

Water molecules within solid and liquid water at low temperature have exceptional characteristics, regarding hydrogen-bonding molecules. They exhibit approximately twice as many hydrogen bonds compared to covalent bonds surrounding each molecule, and possess on average, as many hydrogen bonds as covalent bonds.

Shown left in Figure 3, is the number of hydrogen bonds surrounding each molecule of water when the temperature increases. The line-width indicates the approximate discrepancy between various experimental methods data obtained from ${ }^{27}$. Despite reports of water being surrounded by more than four hydrogen bonds, which cannot be located spatially around the central molecule of water without being accommodated considerably further from the central oxygen, as one or more of the original four hydrogen bonds becoming remarkably weaker. 


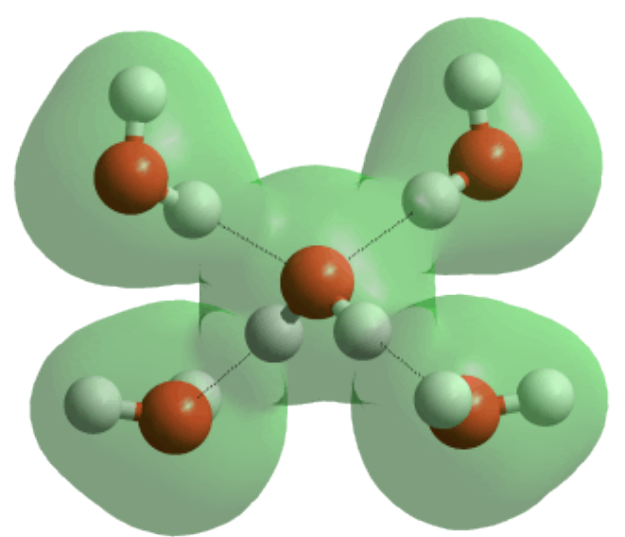

Figure 3. Water molecule and hydrogen bonds

\subsubsection{Dipole moment of water}

Since the two hydrogen atoms share electrons at one end, the molecule is positively charged on one end and negatively on the other. There were suggestions that this can lead the molecule to act as a small bar magnet ${ }^{28}$. This behavior is known as the dipole moment of a molecule. The dipole moment consists of a vectorial quantity and accounts for solubility, which is one of the most relevant properties of water.
Figure 4 indicatesthe similarity of the dipole moment of a water molecule to that of a magnet, as reported by ${ }^{28}$.

According to ${ }^{29}$, polar molecules reach distinctive orientation when exposed to a magnetic field. The higher the magnetic field is, the greater the number of dipoles oriented in the direction of the field can be.

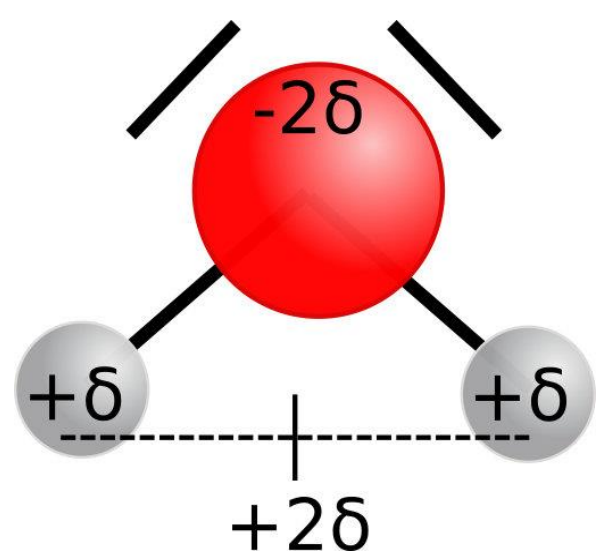

Figure 4. Water molecules. Dipole moment of a molecule (Water's Properties Tutorial, 2004

\subsection{Electrochemical experimental methods}

The electrochemical measurements were carried out in a classic three-electrode cell, by using Volta lab 40 (Tacussel-Radiometer PGZ301) potentiostatgalvanostat, monitored by option analysis software model (Volta master 4) at the stationary condition. The impedance diagrams were recorded in $100 \mathrm{kHz}$ $10 \mathrm{MHz}$ frequency range with 10 points per decade and $10 \mathrm{mV}$ (peak to peak) amplitude of the excitation signal.

\section{Results and Discussion}

\subsection{Impedance spectroscopy studies}

Impedance spectroscopy has been extensively employed to examine the properties of electric materials and electrochemistry systems. Generally, impedance spectroscopy measurements are conducted to identify the physical processes and to evaluate different electrical parameters appropriate for the electrical system under study.
The AC conductivity was estimated from the real and the imaginary parts of the impedance spectra plotted over a study range magnetization time by using the following equation ${ }^{30}$ :

$\sigma_{a c}^{\prime}(\omega)=\frac{e}{S} * \frac{Z^{\prime}}{Z^{\prime 2}+Z^{\prime 2}}$

The frequency dependence of AC conductivity in tap water at various time of magnetization is depicted in Figure 5.

The analysis of Figure 5 indicates that the conductivity is independent of frequency in the lowfrequency regime. Indeed, the magnetization of water can increase the mobility of water through the conductivity, since the resistance decreases with increasing frequency. Furthermore, the conductivity of magnetized water depends on the magnetization as shown in Figure 6 . Note that the frequency ranges between $100 \mathrm{~Hz}$ and $100 \mathrm{KHz}$. 


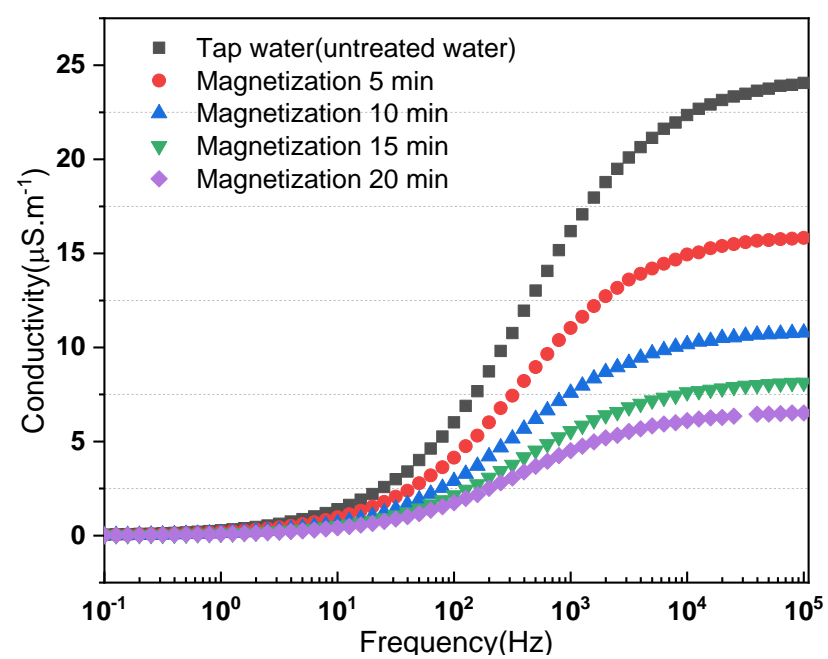

Figure 5. Variation of the conductivity of all samples

The increase in frequency is associated with a rise in conductivity. It is interesting to mention that the electromagnetic field has clear and tangible effects (Figure 6). Besides, one may suggest that the electromagnetic field has a direct impact on the dipole moment of the water molecule. Thus, on the water clusters, the bonds of the compositions become closer to tap water, and the hydrogen bonds are reinforced.

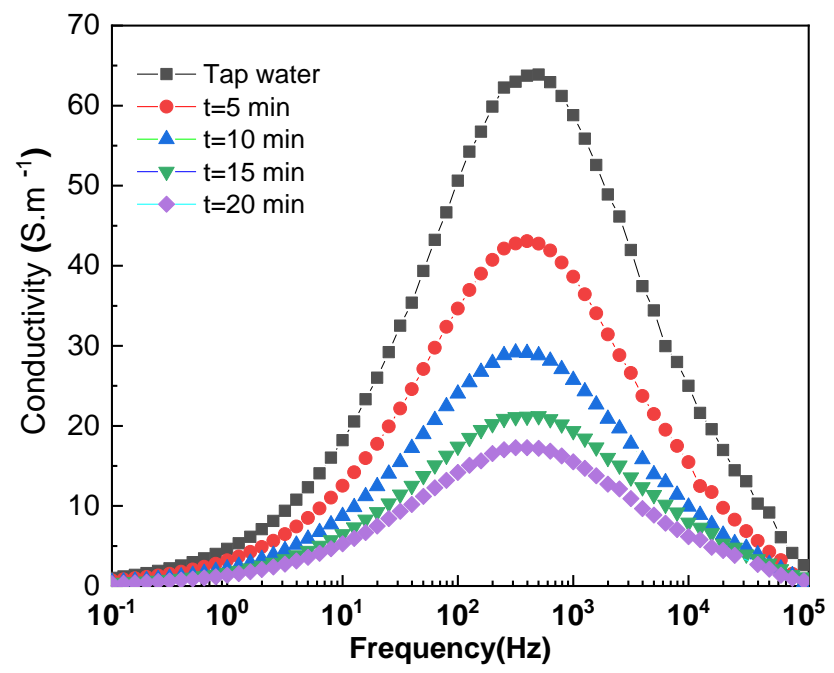

Figure 6. Variation of imaginary part of conductivity as a function of frequency

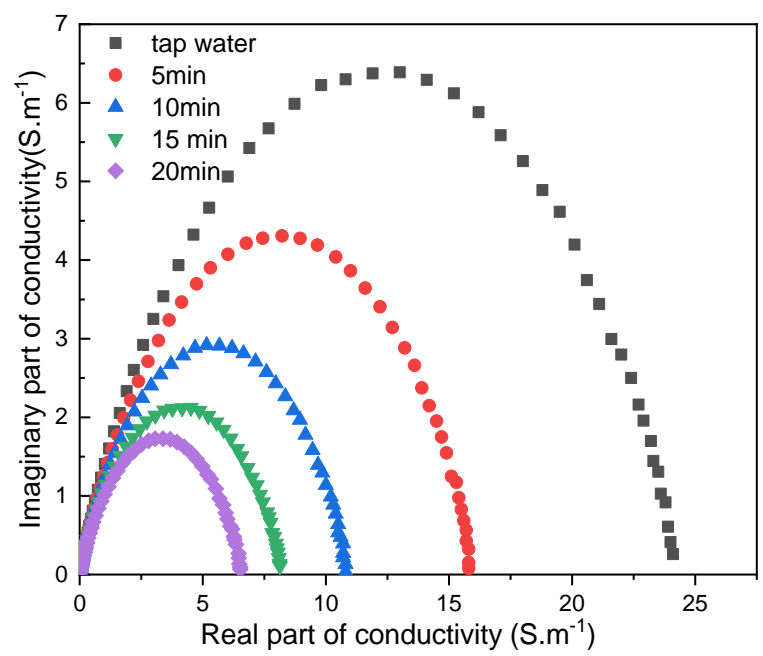

Figure 7. Evolution of the imaginary part as a function the real part of conductivity 
Figures 6 and 7 show the real part of the conductivity and the imaginary part as a function of the real part of conductivity. These figures demonstrate that the relaxation frequency of the magnetized water is unchanged, which implies the absence of deformation

Figure 8 indicates the conductivity cell with a polarization effect and its electric model and the liquid column resistance. The Rcis attributed to the resistance of the liquid column ${ }^{31}$; the RP1 represents the resistor of polarization of electrodepositive and RP2 accounts for resistance of polarization of the negative electrode. A Constant Phase Element (CPE)reflects a double layer capacity distributed by frequency. The CPEis more versatile in approximating dispersive impedance spectra than the "ideal" capacitanceC ${ }^{32}$. Given below is an equation that defines the impedance of a CPE(Eq. (2)):

$Z_{C P E}=Q^{-1}(j w)^{-n}$

Where $\mathrm{Q}$ is a real constant independent of the frequency, $\mathrm{n}$ is an exponent which depends on the in the structure of the water when it is under the circulation of an electromagnetic field. It can be thus suggested that this behavior is the result of the rearrangement of water clusters.

frequency. Regarding $\mathrm{n}$ values, the CPE is replaced by a classical element of electrical circuits: capacity $\mathrm{C}$ $(\mathrm{n}=1)$, resistance $\mathrm{R}(\mathrm{n}=0)$ and inductance $\mathrm{L}$ $(n=-1)$. The value of $n=0.5$ is interpreted by the impedance of Warburg (W). The other values of $n$ designate in an approximate way some other types of frequency distribution behavior of $\mathrm{C}, \mathrm{R}, \mathrm{L}$ or $\mathrm{W}$ with the distributed parameters. Capacitive semicircle dispersion is therefore related to heterogeneity due to surface roughness, impurities or dislocations 33-35 fractal structure ${ }^{36-38}$, adsorption of the inhibitor and the formation of a porous film ${ }^{29,35}$. The fitting and adjustment of impedance spectra were performed using the Zview software version 2.2, in coordination with the equivalent circuit shown in Figure 8.

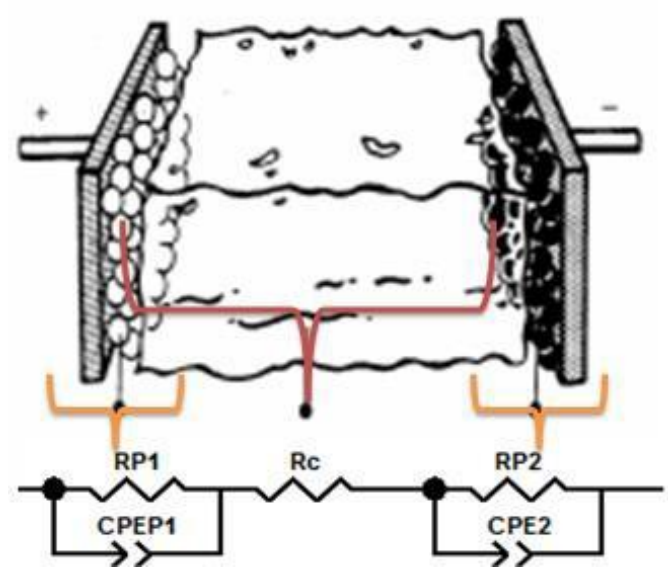

Figure 8. Electrical equivalent circuit used for adjusting the impedance data

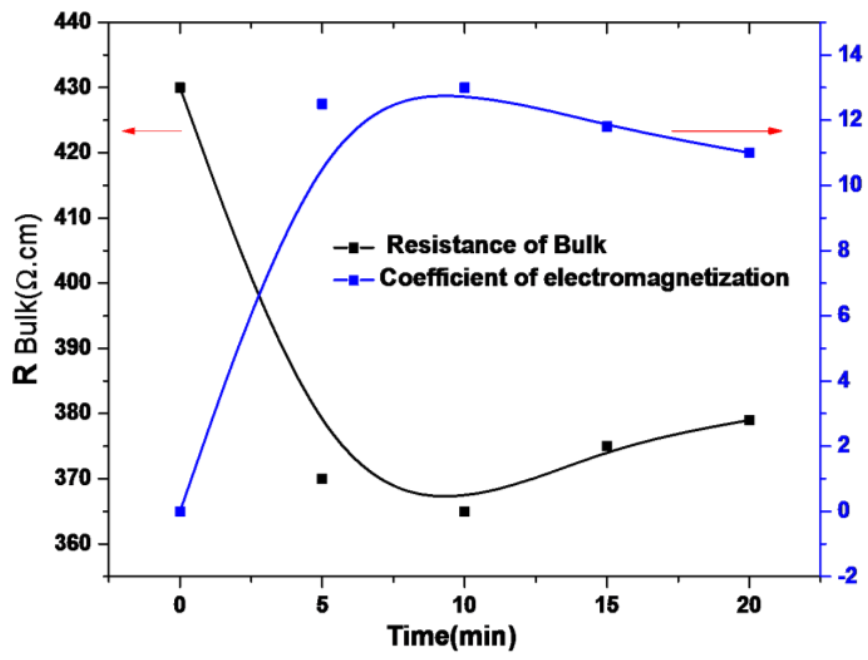

Figure 9. Variations of the electromagnetic field effect of water with increasing exposure time and the resistor of the liquid column 


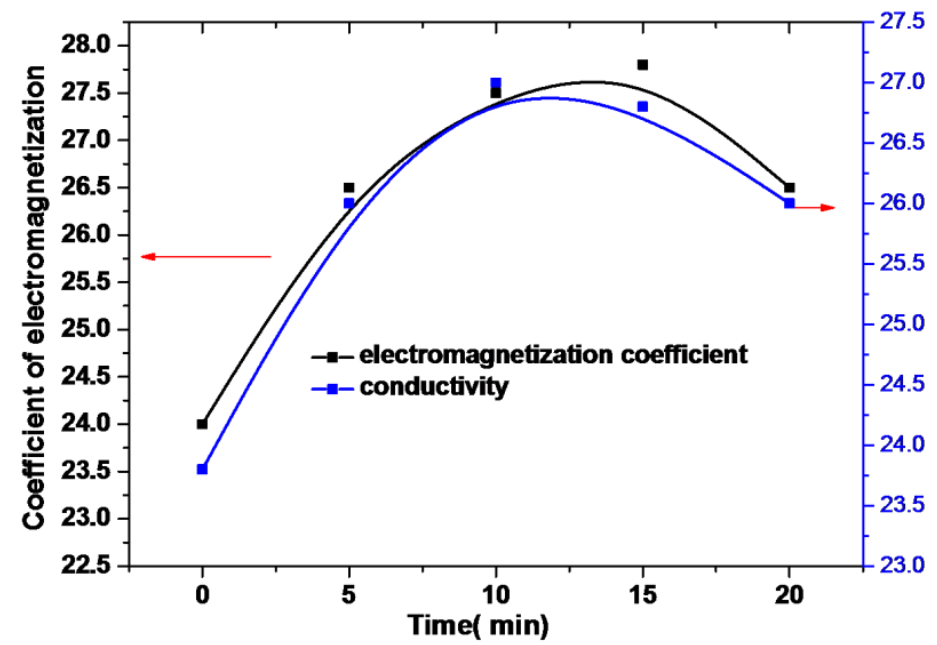

Figure 10. Variations of the effect of the electromagnetic field on the water with time and evolution of the conductivity of the liquid column

The percentage of the coefficient of electro magnetization (Magnetization $(\vec{B})+$ polarization $(\vec{E})$ can be estimated through the fllowing equation ${ }^{31}$ :

$\left(\frac{\Delta R}{R}\right) * 100=\left(\frac{R-R 0}{R 0}\right) * 100$

Where $\mathrm{R}$ and $\mathrm{R}_{0}$ are defined as the charge transfer resistance without and with treatment, respectively. Figure 9 illustrates the variation of the coefficient of electro-magnetization as a function of frequency for various treatment times. Figure 10 provides a comparative analysis of the conductivity of magnetized water and that of tap water.

\section{Mechanism of Change of Electric and dielectric Properties in Water}

In the Figure 11 shows the effect of magnetization and the increase in magnetization time decreases the dielectric constant that is due to the influence of the electromagnetic field on the water is on the organization of the clusters.

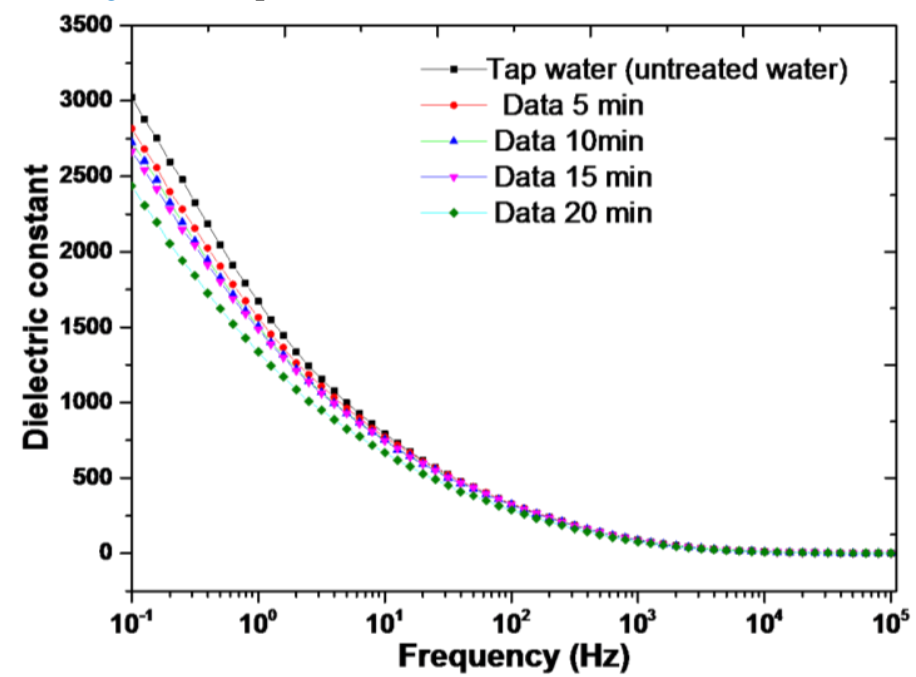

Figure 11. The changes of dielectric constant of magnetized water with increasing magnetized time under action of the electromagnetic field with different frequencies

The change of the dielectric constant according to Figure 11 one notes these mechanisms:

However, what are the reasons for changes in the electric property of water arising from the magnetic field? As it is well known, there are a lot of charged ions, such as $\mathrm{OH}^{-}$and $\mathrm{H}_{3} \mathrm{O}^{+}$or $\mathrm{H}^{+}$as well as clusters including linear and closed hydrogen-bonded chains of molecules in water. The magnetization of water is closely related with the transfers of hydrogen ions or protons $(\mathrm{H}+)$ in the closed hydrogen-bonded chains of molecules according to the theory of magnetization of water ${ }^{39-44}$. In this theory, the proton (or hydrogen ion) current, which occurs in the closed hydrogen-bonded chains arising from the proton transfer between neighboring water molecules under the action of Lorenz force of the magnetic field, results in the magnetization of water due to its interacting with the magnetic field. Thus, we can infer that the electric property of magnetized water will be changed due to the fact that the externally applied electromagnetic field interacts with the ring electric-current elements 
of the proton, which accelerates the shift or jump speed of protons (or hydrogen ions) from one water molecule to other after the hydrogen ions accepted the energy of the externally applied electromagnetic field. At the same time, the velocities of the charged ions will be increased under the action of an electromagnetic field in water; in this case, the electric conductivity of the water will increase.

\section{Conclusion}

In this work, we studied completely the influences of electromagnetic field on the electric and dielectric properties of treated water, including the dielectric constant, resistance and electric conductivity, and measured in detail the changed rules of the electromagnetic property of magnetized water by increasing an externally applied electric field with different frequencies relative to those of treated water. From these investigations, we obtained that the electromagnetic field reduced the dielectric constant and resistance of treated water, and increased its electric conductivity. Meanwhile, we find that the electric conductivity of magnetized water is increased with increasing frequency of externally applied electric field and magnetized time, but its dielectric constant and resistance are decreased with increasing frequency of externally applied electric field and magnetized time. Therefore, we can conclude that the magnetic field really changed the electromagnetic properties of water. Thus, we can affirm that water can be magnetized in a magnetic field; magnetized water has different properties relative to those of pure water. The studied results have important signification in science and will expand the applications of magnetized water in industry, medicine, and biomedicine which will be covered by the next studies.

\section{References}

1- F. Alimi, M. Tlili, M. Ben Amor, C. Gabrielli, G. Maurin, Influence of magnetic field on calcium carbonate precipitation, Desalination, 2007, 206, 163-168.

2- R. Mghaiouini, A. Elaouad, H. Taimoury, I. Sabir, F. Chibi, M. Hozayn, T. Garmim, R. Nmila, H. Rchid, M. Monkade, A. El Bouari, Influence of the Electromagnetic Device Aqua 4D on Water Quality and Germination of Lettuce (Lactuca sativa L.), International Journal of Current Engineering and Technology, 2020, 10.

3- I. Lin. J. Yotvat, Exposure Of Irrigation And Drinking Water To A Magnetic Field With Controlled Power And Direction, Journal of Magnetism and Magnetic Materials, 1990, 83, 525-526.

4- A. De Souza, D. Garcia, L. Sueiro, F. Gilart, E. Porras, Pre-sowing magnetic treatments of tomato seeds increase the growth and yield of plants, Bioelectromagnetics, 2006, 27, 247-257.
5- K. W. Busch, M. A. Busch, Laborator studies on magnetic water treatment and their relationship to a possible mechanism for scale reduction, Desalination, 1997, 109, 131-148.

6- R. Mghaiouini, A. Elaouad, T. Garmim, M. E. Belghiti, E. Valette, C. H .Faure, M. Hozayn, M. Monkade, A. El Bouari, The Electromagnetic Memory of Water at Kinetic Condition, International Journal of Current Engineering and Technology, 2020, 10.

7- Y. Cho, S. Lee, Reduction in the surface tension of water due to physical water treatment for fouling control in heat exchangers, International Communications in Heat and Mass Transfer, 2005, 32, 1-9.

8- S. Nan, W. Yeong-Hwa, M. Chung- Yo, Effect of magnetic water on the engineering properties of concrete containing granulated blast-furnace slag, Cement and Concrete Research, 2000, 30, 599-605.

9- E. Del Giudice, V. Voeikov, A. Tedeschi, The origin and the special role of coherent water in living systems, Fields of the Cell, 2014, 95-111.

10-J. Da Silva, T. da Silva, D. Judit, Impact of magnetic water on plant growth, Environmental and Experimental Biology, 2014, 12, 137-142.

11-L. Montagnier, J. Aissa, E. Del Giudice, C. Lavallee, A. Tedeschi and G. Vitiello, DNA waves and water, Journal of Physics: Conference Series, 2011, 306, 012007.

12-M. Shafiei, N. Ojaghlou, S. G Zamfir, D. Bratko, A. Luzar, Modulation of structure and dynamic of water under alternating electric field and the role of hydrogen bonding, Molecular Physics, 2019, 117, 3282-3296.

13-I. Rad, G. H. Pollack, Cooling of pure water at room temperature by weak electric currents, Journal of Physical Chemistry B, 2018, 7711-7717.

14-S. N. Andreev, V. P. Makarov, V. I. Tikhonov, A. A. Volkov, Ortho and paramolecules of water in electric field, arXiv preprint physics, 2007, 0703038 .

15-I. Danielewicz-Ferchmin, A. R. Ferchmin, Water at ions, biomolecules and charged surfaces, Physics and Chemistry of Liquids, 2004, 42, 1-36.

16-M. Otani, I. Hamada, O. Sugino, Y. Morikawa, Y. Okamoto, T. Ikeshoji, Electrodynamics from first principles, Journal of Phys. Soc. Japan, 2008, 77, 024802.

17-K. Ovchinnikova, G. H. Pollack, Can water store charge, Langmuir, 2009, 25, 542-547.

18-L. J. Michot, F. Villiéras, M. François, I. Bihannic, M. Pelletier, J-M. Cases, Water organization at the solid-aqueous solution interface, Comptes Rendus Geoscience, 2002, 334, 611-631.

19-X. F. Pang, B. Deng, Investigation of changes in properties of water under the action of a magnetic field, Science in China Series G: Physics, Mechanics \& Astronomy, 2008, 51, 1621-1632. 
20-R. D. Ambashta, M. Sillanpää, Water purification using magnetic assistance: a Review, Journal of Hazardous Materials, 2010,180, 38-49.

21-Y. Ikezoe, N. Hirota, J. Nakagawa, K. Kitazawa, Making water levitate, Nature, 1998, 393, 749-750

22-K. X. Zhou, G. W. Lu, Q. C. Zhou, J. H. Song, S. T. Jiang, H. R. Xia, Monte Carlo simulation of liquid water in a magnetic field, Journal of Applied Physics, 2000, 88, 1802-1805.

23-R. Cai, H. Yang, J. He, W. Zhu, The effects of magnetic fields on water molecular hydrogen bonds, Journal of Molecular Structure, 2009, 938, 15-19.

24-G. Garcetti, Water is Key - Photo Essay, Journal of Cleaner Production, 2013, 60, 216-224.

25-A. Vegiri, Reorientation relaxation and rotational-translational coupling in water clusters in a dc external electric field, Journal of Molecular Liquids, 2004, 110, 155-168.

26-X. Shen, increased dielectric constant in the water treated by extremely low-frequency electromagnetic field and its possible biology implication, Journal of Physics: Conference Series, 2011, 329, 012019.

27-A. Rastogi, A. K. Ghosh, S. J. Suresh, Hydrogen bond interactions between water molecules in bulk liquid, near electrode surfaces around ions, Thermodynamics - Physical Chemistry of Aqueous Systems, 2011, 351-364.

28-E. V. Tsiper, Polarization forces in water derived from single-molecule data, Physical Review Letters, 2005, 94, 013204.

29-C. Quinn, C. T. Molden, C. H. Sanderson, Magnetic treatment of water prevents mineral build-up, Iron and Steel Engineer, 1997.

30-B. Silva, J. C. Q. Neto, D.F.S. Petria, The effect of magnetic field on ion hydration and sulfate scale formation, Colloids and Surfaces A: Physicochemical and Engineering Aspects, 2015, $465,175-183$.

31-S. Ueno, Studies on magnetism and bioelectromagnetic for 45 years: from magnetic analog memory to human brain stimulation and imaging, Bioelectromagnetics, 2012, 33, 3-22.

32-A. Elmelouky, A. Mortadi, R. El Moznin, E. Chahid, R. Lahkale, Dielectric spectroscopy studies in $\mathrm{Zn}_{2} \mathrm{FeNO}_{3}, \mathrm{Zn}_{2} \mathrm{AlNO}_{3}$ and $\mathrm{Zn} 2 \mathrm{Fe}_{0.5} \mathrm{Al}_{0.5} \mathrm{NO}_{3}$, Int. J. Adv. Res., 2015, 3, 465-475.
33-S. Murad, The role of magnetic fields on the membrane-based separation of aqueous electrolyte solutions, Chm. Phys. Lett, 2006, 417, 465-470.

34-R. Cai, H. Yang, J. He, W. Zhu, The effects of magnetic fields on water molecular hydrogen bonds, J. Mol. Struct., 2009, 938, 15-19.

35-A. Seyfi, R. Afzalzadeha, A. Hajnorouzi, Increase in water evaporation rate with increase in static magnetic field perpendicular to the water-air interface, Chem. Eng. Process., 2017, 120, 195-200.

36-A. Szkatula, M. Balanda, M. Kope, Magnetic treatment of industrial water. Silica activation, Eur. Phys. J. Appl. Phys., 2002, 18, 41-49.

37-M. Zielinski, A. Cydzik-Kwiatkowska, M. Zielinska, M. D. bowski, P. Rusanowska, J. Kopanska, Nitrification in activated sludge exposed to static magnetic field. Water Air Soil Pollut., 2017, 228, 126.

38-Y. Q. Liu, S. Suhartini, L. Guo, Y. Xionget, Improved biological wastewater treatment and sludge characteristics by applying magnetic field to aerobic granules, Aims Bioeng., 2016, 3, 412-424.

39-J. R. Errington, P. G. Debenedetti, Relationship between structural order and the anomalies of liquid water, Nature, 2001, 409, 318-321.

40-A. Khan, A liquid water model: Density variation from supercooled to superheated states, prediction of $\mathrm{H}$-bonds, and temperature limits, Journal of Physical Chemistry, 2000, 104, 11268-11274.

41-S. Rai, U. P. Singh, K. P. Singh, A. Singh, Germination responses of fungal spores to magnetically restructured water, ElectroMagnetobiol., 1994, 13, 237-246.

42-H. Schober, M. M. Koza, A. Tölle, C. Masciovecchio, F. Sette, F. Fujara, Crystallike high frequency phonons in the amorphous phases of solid water, Physical Review Letters, 2000, 85, 4100-4103.

43-K. Kitazawa, Y. Ikezoe, H. Uetake, N. Hirota, Magnetic field effects on water, air and powders, Physica B: Condensed Matter, 2001, 294, 709-714.

44-R. A. Mayanovic, A. J. Anderson, W. A. Bassett, Hydrogen bond breaking in aqueous solutions near the critical point, Chemical Physics Letters, 2001, 336, 212-218. 